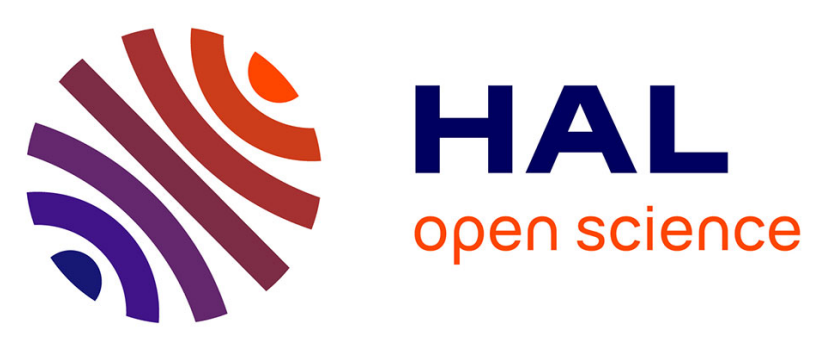

\title{
Optical properties of tensile-strained and relaxed Ge films grown on InGaAs buffer
}

V. A. Volodin, L. V. Sokolov, M. A. Pytyato, N. I. Petikov, Mathieu Stoffel, Hervé Rinnert, Michel Vergnat

\section{- To cite this version:}

V. A. Volodin, L. V. Sokolov, M. A. Pytyato, N. I. Petikov, Mathieu Stoffel, et al.. Optical properties of tensile-strained and relaxed Ge films grown on InGaAs buffer. Journal of Applied Physics, 2014, 115 (5), 10.1063/1.4864466 . hal-01284791

\section{HAL Id: hal-01284791 \\ https://hal.science/hal-01284791}

Submitted on 5 Jul 2019

HAL is a multi-disciplinary open access archive for the deposit and dissemination of scientific research documents, whether they are published or not. The documents may come from teaching and research institutions in France or abroad, or from public or private research centers.
L'archive ouverte pluridisciplinaire HAL, est destinée au dépôt et à la diffusion de documents scientifiques de niveau recherche, publiés ou non, émanant des établissements d'enseignement et de recherche français ou étrangers, des laboratoires publics ou privés. 


\title{
Optical properties of tensile-strained and relaxed Ge films grown on InGaAs buffer
}

\author{
V. A. Volodin, ${ }^{1,2, a)}$ L. V. Sokolov, ${ }^{1}$ M. A. Pytyato, ${ }^{1}$ N. I. Petikov, ${ }^{1}$ M. Stoffel, ${ }^{3}$ H. Rinnert, ${ }^{3}$ \\ and $\mathrm{M}$. Vergnat ${ }^{3}$ \\ ${ }^{1}$ A.V. Rzhanov Institute of Semiconductor Physics, Siberian Division of the Russian Academy of Sciences, \\ Lavrenteva 13, Novosibirsk 630090, Russia \\ ${ }^{2}$ Novosibirsk State University, Pirogova Street, 2, 630090 Novosibirsk, Russia \\ ${ }^{3}$ Université de Lorraine, Institut Jean Lamour UMR CNRS 7198, B.P. 70239, 54506 Vandouvre-lès-Nancy \\ Cedex, France
}

(Received 4 December 2013; accepted 23 January 2014; published online 6 February 2014)

\begin{abstract}
$\mathrm{GeO}_{2} / \mathrm{Ge} / \mathrm{In}_{\mathrm{x}} \mathrm{Ga}_{1-\mathrm{x}} \mathrm{As}$ heterostructures grown on (100) GaAs substrates were studied using Raman spectroscopy and photoluminescence (PL) spectroscopy. Both nearly pseudomorphic tensile-strained and nearly completely relaxed Ge films were grown and studied. The maximum tensile strain for Ge films with a thickness of $\approx 7 \mathrm{~nm}$ reaches $2.25 \%$. PL data confirm the conclusions that the band gap offset of $\mathrm{Ge} / \mathrm{In}_{\mathrm{x}} \mathrm{Ga}_{1-\mathrm{x}} \mathrm{As}$ is sensitive to the polarity of the bonds at the interface, and also to a parameter of $\mathrm{x}$ and the relaxation of strain. Depending on these parameters, the $\mathrm{Ge} / \mathrm{In}_{\mathrm{x}} \mathrm{Ga}_{1-\mathrm{x}} \mathrm{As}$ may be type-I or type-II heterostructures. (C) 2014 AIP Publishing LLC. [http://dx.doi.org/10.1063/1.4864466]
\end{abstract}

\section{INTRODUCTION}

The applying of strain is one of the ways to modulate the band structure in semiconductors. Elastically stretched $\mathrm{Ge}$ is a promising material for microelectronics and optoelectronics. Fischetti et al. ${ }^{1}$ have shown theoretically that the biaxial tensile stress in Ge significantly increases the mobility of both electrons and holes. Theoretical calculations predict a decrease of energy for the $\Gamma$-valley in the conduction band and the transformation of $\mathrm{Ge}$ in the direct-gap material for its biaxial stretching at $\sim 2 \%$. $^{1-3}$

Growth of films on an artificial substrate with a different lattice constant is an approach of getting strongly strained materials. In this case, if the lattice constant of substrate is more than that of the film and the thickness of grown film does not exceed critical value, the film remains pseudomorphically biaxially stretched. For example, the relaxed $\mathrm{Sn}_{\mathrm{x}} \mathrm{Ge}_{1-\mathrm{x}}$ films grown on $\mathrm{Si}$ substrate were used as artificial substrates for the growth of tensile-strained Ge films. ${ }^{4,5}$ However, because of the limited solubility of Sn in germanium, tensile deformation in Ge films for such a system does not exceed $0.71 \%$. Huo et $a{ }^{6}{ }^{6}$ used as artificial substrates heterostructures $\operatorname{In}_{\mathrm{x}} \mathrm{Ga}_{1-\mathrm{x}} \mathrm{As} / \mathrm{GaAs}$. They have enlarged concentration of indium in each $200 \mathrm{~nm}$ buffer layers of $\mathrm{In}_{\mathrm{x}} \mathrm{Ga}_{1-\mathrm{x}} \mathrm{As}$, and after three stages they have reached composition $\mathrm{In}_{0.4} \mathrm{Ga}_{0.6} \mathrm{As}$. In the case of full relaxation, the lattice constant of such buffer layer should be $2.8 \%$ larger than the lattice constant of Ge. The Ge films with largest tensile strain $(2.33 \%)$ were grown on such buffer. ${ }^{6}$ They have observed 20-times growth of photoluminescence (PL) intensity at low temperature from such stretched Ge films. ${ }^{6}$

It is known that strong doping of Ge by donors leads to reaching a high concentration of electrons in the $\Gamma$-valley of the conduction band and can enhance direct transitions in

${ }^{\text {a)} E-m a i l: ~ v o l o d i n @ i s p . n s c . r u . ~}$
Ge. The authors of Ref. 7 report on strong PL $(\sim 1600 \mathrm{~nm})$ at room temperature in n-type Ge films with $0.5 \%$ tensile strain. To enhance optic transitions in indirect semiconductors, one can use softening of the quasi-momentum conservation law by additional scattering (defects or roughness of surface). The authors of Ref. 8 studied the influence of defects and roughness of the $\mathrm{Ge} / \mathrm{Al}_{2} \mathrm{O}_{3}$ heterostructure on optical transitions and have observed both direct and indirect transitions in the PL and electroluminescence spectra. The authors of Ref. 9 have applied the original method of changing the tensile stress in the Ge films using nanomembranes, and have observed PL growth of direct optical transitions with increasing tensile strain in the Ge films. The group of Professor Kimerling is the most advanced in the practical use of the effects of tensile strain and doping of Ge films; they reported on creation of the laser using direct optical transitions in $\mathrm{Ge}$ films. $^{10-12}$

But the optical properties of $\mathrm{Ge} / \mathrm{In}_{\mathrm{x}} \mathrm{GaAs}_{1-\mathrm{x}}$ heterostructures have not been studied enough. For example, it was reported in Ref. 13 that the band gap offset between Ge and $\mathrm{In}_{\mathrm{x}} \mathrm{GaAs}_{1-\mathrm{x}}$ may vary depending on the polarity of the $\operatorname{In}_{\mathrm{x}} \mathrm{GaAs}_{1-\mathrm{x}}$ surface, and this leads to the fact that such heterostructures can be type-I or type-II. Our work is an attempt to investigate the optical transitions in nearly pseudomorphic stretched films of Ge on $\operatorname{In}_{\mathrm{x}} \mathrm{GaAs}_{1-\mathrm{x}}$, and in films, in which the tensile stress is relaxed.

\section{EXPERIMENTAL}

The peculiarity of our experiments was growth stages of structures $\mathrm{Ge} / \mathrm{InGaAs} / \mathrm{GaAs}$ in different molecular beam epitaxy (MBE) chambers with intermediate removal of structures on the atmosphere. After growing of $\operatorname{In}_{x} \mathrm{Ga}_{1-\mathrm{x}} \mathrm{As}$ buffer layer $(\mathrm{x}=0.33-0.37$, thickness $\sim 1000 \mathrm{~nm})$ on GaAs (001) substrate, the structure was covered with a thin layer of As, to prevent the surface from contamination. After transfer to the MBE chamber for growing Ge, structure 
TABLE I. The parameters of studied samples.

\begin{tabular}{|c|c|c|c|c|c|}
\hline Sample & $\begin{array}{r}\mathrm{x} \text { in } \mathrm{In}_{\mathrm{x}} \mathrm{Ga}_{1-\mathrm{x}} \mathrm{As} \\
\text { (x-ray data) }(\%)\end{array}$ & $\begin{array}{c}\text { Relaxation of stress } \\
\text { in } \operatorname{In}_{x} \mathrm{Ga}_{1-x} \mathrm{As}, \mathrm{x} \text {-ray data }(\%)\end{array}$ & $\begin{array}{l}\text { Thickness of } \mathrm{Ge}(\mathrm{nm}) / \text { and } \\
\text { native oxide } \mathrm{GeO}_{2}\end{array}$ & $\begin{array}{l}\text { Maximal strain (\%) } \\
\quad \text { (calculated) }\end{array}$ & $\begin{array}{l}\text { Strain tensile } \\
\text { (Raman data) }\end{array}$ \\
\hline A & 37 & 88 & $7-8 / 2-3$ & 2.33 & 2.25 \\
\hline B & 37 & 88 & $8-9 / 2-3$ & 2.33 & 1.0 \\
\hline C & 33 & 88 & $10-11 / 2-3$ & 2.08 & 0.35 \\
\hline
\end{tabular}

InGaAs/GaAs was heated to a temperature of about $500{ }^{\circ} \mathrm{C}$ so that arsenic together with the oxides and contaminants desorb. Surface reconstruction $2 \times 4$ was observed from the data of electron diffraction. The Ge films were grown at the substrate temperature of $350^{\circ} \mathrm{C}$. The source of $\mathrm{Ge}$ was calibrated, so the thickness of Ge film was proportional to time of growth. The thicknesses of the Ge films were also checked from analysis of spectral ellipsometry data. According to these data, it was also determined that Ge films were coated with a thin native oxide layer. Some parameters of the samples are shown in Table I.

The strain in Ge films was studied using Raman scattering spectroscopy in the backscattering geometry. Raman spectrometer T64000 (Horiba Jobin Yvon) with microRaman setup (based on Olympus optical microscope) equipped with a liquid nitrogen cooled CCD matrix detector was used. The sample was excited by the $514.5 \mathrm{~nm}$ line of an $\mathrm{Ar}^{+}$laser. The spectral resolution was better than $1 \mathrm{~cm}^{-1}$. The laser radiation does not cause significant heating of the samples, since the laser power reaching the sample was $2 \mathrm{~mW}$, and the diameter of the laser beam on a sample was $10 \mu \mathrm{m}$. The optical properties of the heterostructures were also investigated using PL spectroscopy. A laser diode emitting at $488 \mathrm{~nm}$ was used to excite the luminescence. The PL spectra were measured at room temperature, using a monochromator with grating 600 lines/mm and a liquid nitrogen cooled InGaAs detector. All PL spectra were corrected from the response of the detector. The cryostat was used to study the temperature dependence of the PL; the stability of the temperature was $\pm 0.5 \mathrm{~K}$.

\section{RESULTS AND DISCUSSION}

Figure 1(a) shows the Raman spectra of bulk Ge and $\mathrm{Ge} / \mathrm{InGaAs} / \mathrm{GaAs}$ heterostructures. The peaks with frequencies $\sim 280 \mathrm{~cm}^{-1}$ correspond to Raman scattering by longitudinal optical (LO)-type phonons of InGaAs solid alloy. Their frequencies depend on strain and composition of the alloy. One can see that the peaks between 290 and $301 \mathrm{~cm}^{-1}$ corresponding to scattering by the vibrations of Ge-Ge bonds are shifted compared with unstrained bulk Ge. Shifts are 9.5, 4.2, and 1.5 reversed centimeters for samples A, B, and C, respectively. It is known that mechanical stresses lead to strain and change of the bond length. Due to anharmonicity, the stiffness of the distorted bonds is changed, and thus, the phonon frequencies are also changed. In order to calculate the dependency of the phonon frequencies on the strain tensor, it is necessary to know the parameters of anharmonicity. In pioneering works, this problem is solved for crystals with a diamond-type lattice ${ }^{14}$ and zinc-blende lattice. ${ }^{15}$ If one substitutes the parameters of the anharmonicity (in high-symmetry cubic crystal there are only three parameters, which are referred as $\mathrm{p}, \mathrm{q}$, and $\mathrm{r}$ ) in the equations of force matrix, the optical phonon frequencies at the center of the Brillouin zone are obtained from the so-called secular equation. The determinant of the following matrix ${ }^{14,15}$ should be equal to zero:

$$
\left|\begin{array}{ccc}
p \varepsilon_{x x}+q\left(\varepsilon_{y y}+\varepsilon_{z z}\right)-\lambda & 2 r \varepsilon_{x y} & 2 r \varepsilon_{x z} \\
2 r \varepsilon_{x y} & p \varepsilon_{y y}+q\left(\varepsilon_{x x}+\varepsilon_{z z}\right)-\lambda & 2 r \varepsilon_{y z} \\
2 r \varepsilon_{x z} & 2 r \varepsilon_{y z} & p \varepsilon_{z z}+q\left(\varepsilon_{x x}+\varepsilon_{y y}\right)-\lambda
\end{array}\right|=0 .
$$

Here, $\varepsilon_{\alpha \beta}$ are the components of the strain tensor, $\lambda=\Omega^{2}$ $-\omega_{0}^{2}, \Omega$ is the phonon frequency of the strained crystal, $\omega_{0}$ is the phonon frequency of the unstrained, bulk crystal. Usually, the difference between $\Omega$ and $\omega_{0}(\Delta \Omega)$ is small, thus $\Delta \Omega$ can be expressed as $\Delta \Omega=\lambda / 2 \omega_{0}$. In the case of biaxial strain $\left(\varepsilon_{x x}=\varepsilon_{y y}\right)$ without twisting and shifting $\left(\varepsilon_{x y}=\varepsilon_{y z}=\varepsilon_{x z}=0\right)$, the determinant is easily solved. There are two solutions: for doublet $\left(\varepsilon_{x x}(p+q)+\varepsilon_{z z} q-\lambda=0\right)$; and for singlet $\left(2 \varepsilon_{x x} q+\varepsilon_{z z} p-\lambda=0\right)$. The ratio between $\varepsilon_{\mathrm{xx}}$ and $\varepsilon_{\mathrm{zz}}$ is defined by Poisson's ratio. In the case of non-deformed crystal diamond-type lattice, LO and transverse optical (TO) phonons are degenerated at the center of the Brillouin zone. To analyze the value of phonon frequency shifts versus strain, it is proper to written expression, wherein the strain tensor is expressed as a percentage, and the frequency is expressed in reversed centimeters. In our case of backscattering from (001) oriented Ge film, the LO phonons (both wave-vector and vector of atomic displacement are directed along (001) axis) are active in Raman scattering. For such long-wave LO phonon, ${ }^{16-18}$

$$
\Delta \Omega\left(\mathrm{Ge}_{\mathrm{LO}}\right)=-4.2 \varepsilon_{x x} .
$$

The minus sign corresponds to the fact that the positive deformation (stretching) decreases the phonon frequency. Therefore, according to Raman scattering data, the lateral $\left(\varepsilon_{x x}=\varepsilon_{y y}\right)$ strain for Ge films in samples $\mathrm{A}, \mathrm{B}$, and $\mathrm{C}$ are 

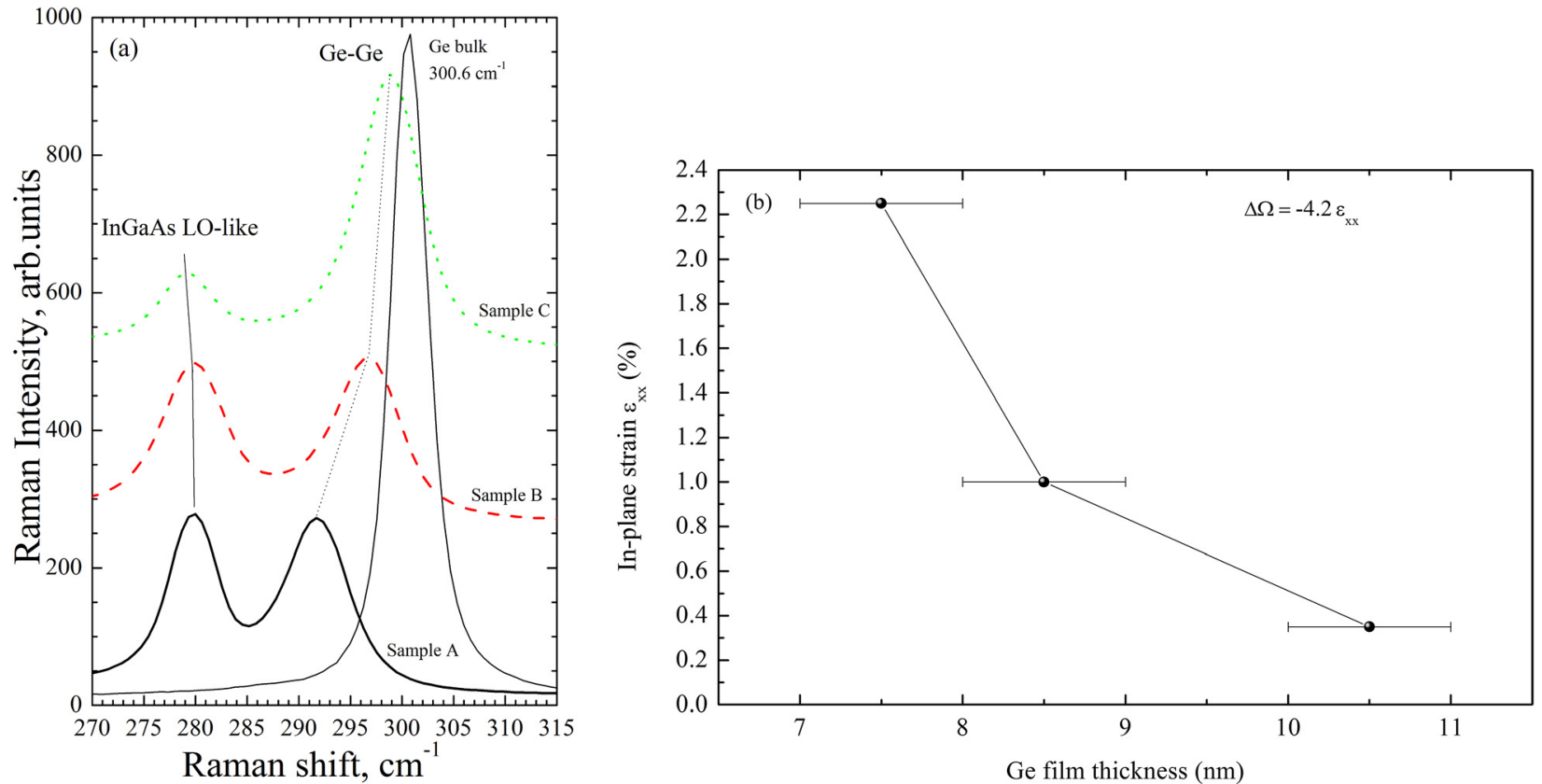

FIG. 1. (a) Raman spectra of unstrained bulk Ge and Ge/ $/ n_{x} \mathrm{Ga}_{1-\mathrm{x}} \mathrm{As}$ heterostructures. (b) Modulus of lateral strain in Ge films versus thickness.

$2.25 \%, 1 \%$, and $0.35 \%$, respectively (Table I and Fig. 1(b)). As one can see in Table I, maximal strain is equal for samples A and B, but Ge film in sample B is more relaxed. For the Ge films, elastically deformed by the amount of $2.33 \%$, the equilibrium critical thickness for plastic relaxation due to a $60^{\circ}$ dislocation is $7 \mathrm{~nm} .{ }^{19}$ As a rule, the process of relaxation of epitaxial films occurs at thicknesses exceeding the critical value due to kinetic restrictions of the introduction of dislocations. However, when the film grows on the relaxed buffer such as InGaAs, kinetic restrictions are removed due to large number of threading dislocations that occurred at the stage of relaxation of the buffer layer. As seen from Table I and Fig. 1(b), the thickness of the sample A is very close to the critical value, while the thickness of sample B is slightly greater than the critical value. This may explain the fact that sample A is pseudomorphic, while sample B is half-relaxed.

Figure 2 shows the PL spectra of $\mathrm{Ge} / \mathrm{In}_{\mathrm{x}} \mathrm{Ga}_{1-\mathrm{x}}$ As heterostructures and unstrained bulk $\mathrm{Ge}$ registered at $10 \mathrm{~K}$. The laser fluence was $500 \mathrm{~kW} / \mathrm{m}^{2}$. For convenience, the PL intensities are shown in logarithmic scale. No PL signal was observed for bulk Ge. Lieten $e t a l .^{20}$ have recently shown that the PL of intrinsic bulk Ge is observed rather between $1650 \mathrm{~nm}$ and $1900 \mathrm{~nm}$, which is obviously out of the detection range of our InGaAs detector. One can see the peaks at $1155 \mathrm{~nm}$ $(1073 \mathrm{meV}), 1230 \mathrm{~nm}(1008 \mathrm{meV})$, and $1500 \mathrm{~nm}(827 \mathrm{meV})$ in the PL spectrum of sample A. We shall denote them as peaks 1,2 , and 3 , respectively. One can see that peak 2 is shifted towards $1255 \mathrm{~nm}(988 \mathrm{meV})$ for sample B, and peaks 1 and 2 are not observed in spectrum of sample C. The PL peak with position of about $1250 \mathrm{~nm}$ was also observed by Pavarelli et al. ${ }^{13}$ for heterostructure in which the Ge layer was inserted between the $\mathrm{In}_{0.3} \mathrm{Ga}_{0.7}$ As layers. They connected it to optical transitions between electrons localized in the Ge layer and holes localized in the $\mathrm{In}_{0.3} \mathrm{Ga}_{0.7}$ As layers. They have studied that the position of this peak depends on intensity of exiting laser source and have observed that blue-shift is proportional to the cube root of the laser fluence. According to the model proposed in Ref. 21, such dependence suggests that $\mathrm{In}_{0.3} \mathrm{Ga}_{0.7} \mathrm{As} / \mathrm{Ge} / \mathrm{In}_{0.3} \mathrm{Ga}_{0.7} \mathrm{As}$ is a type-II heterostructure.

Figure 3 shows the PL spectra of sample B, depending on the laser fluence. One can see no significant shift of peaks 1 and 2 when laser fluence increases almost two orders of magnitude. In Ref. 13, it was reported about $60 \mathrm{meV}$ blueshift when the laser fluence was increased by four orders of magnitude. Lack of effect of a shift in our sample will be discussed below.

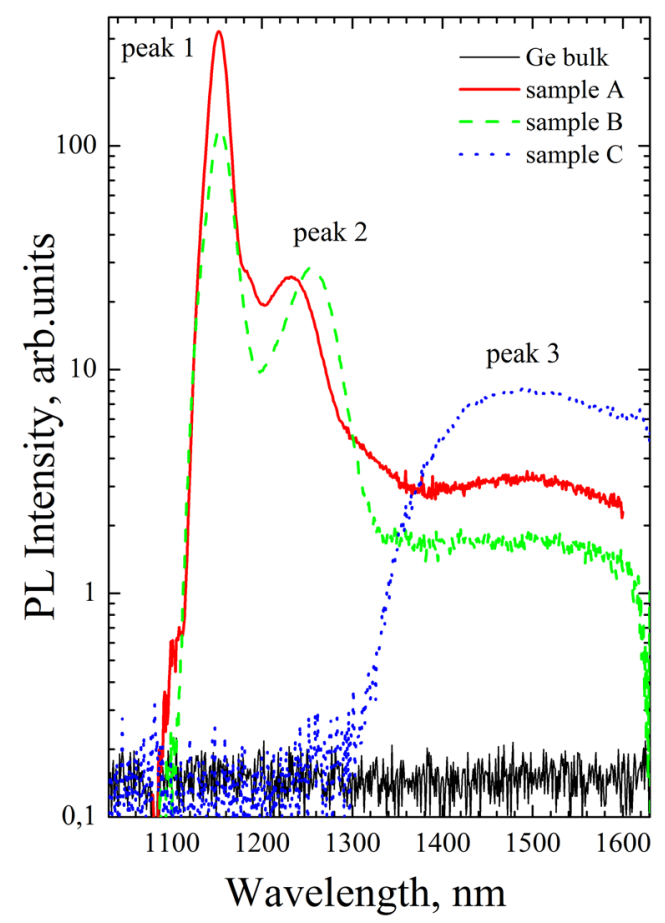

FIG. 2. PL spectra of unstrained bulk Ge and $\mathrm{Ge} / \mathrm{In}_{\mathrm{x}} \mathrm{Ga}_{1-\mathrm{x}} \mathrm{As}$ heterostructures at temperature $10 \mathrm{~K}$. 


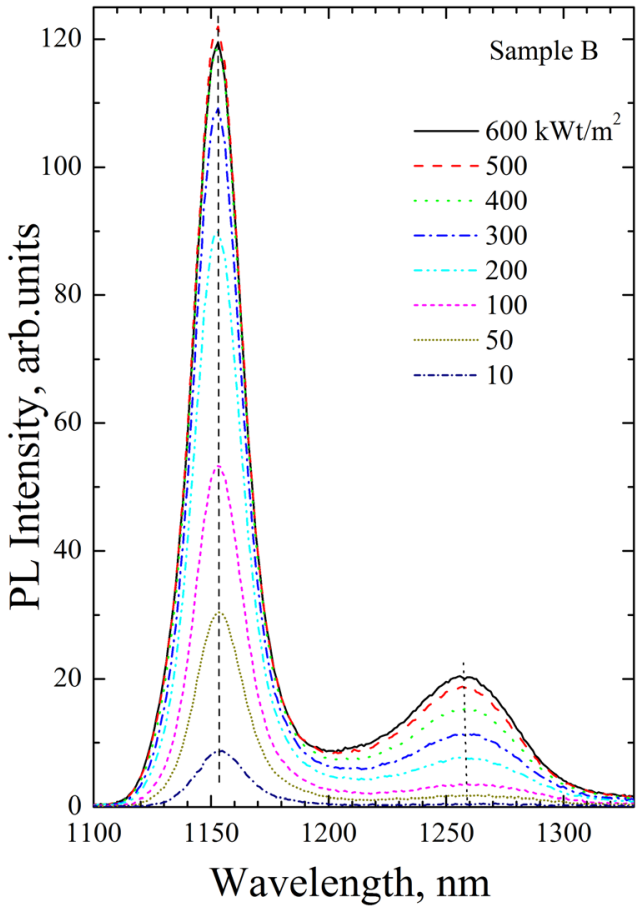

FIG. 3. PL spectra of sample B at $10 \mathrm{~K}$ at different laser fluences.

Figures 4 and 5 show the PL spectra at different temperatures. One can see that, with increasing temperature, the red-shift of peak 1 is small, while peaks 2 and 3 are strongly red-shifted. It is known that the band gap of Ge depending on the absolute temperature as ${ }^{22,23}$

$$
\mathrm{E}(\mathrm{Ge}, \mathrm{meV})=742-\frac{0.48 T^{2}}{(T+235)} .
$$

For $\operatorname{In}_{\mathrm{x}} \mathrm{Ga}_{1-\mathrm{x}} \mathrm{As}$, band gap depends on both composition and the temperature as ${ }^{24}$

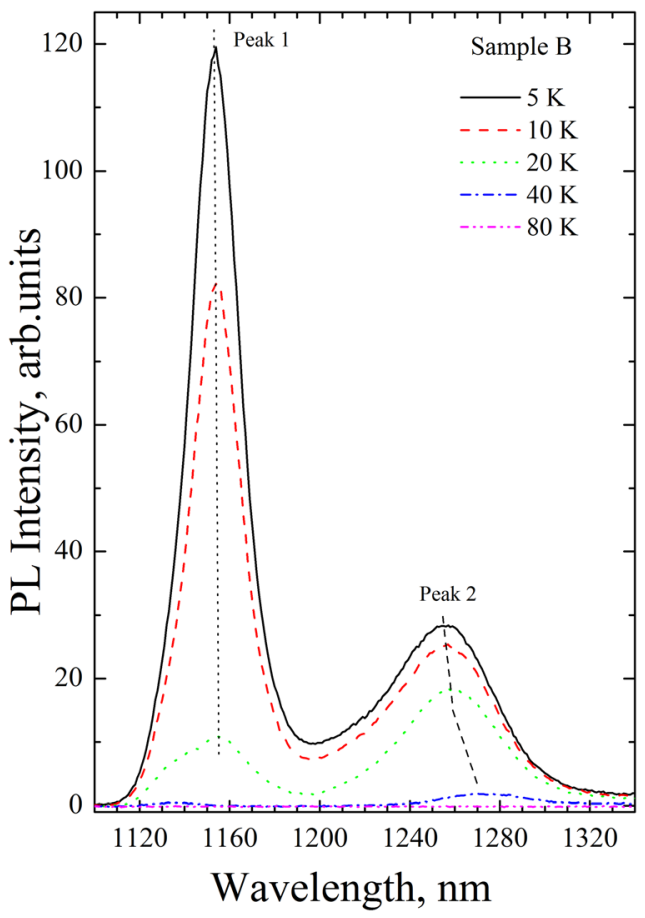

FIG. 4. PL spectra of sample B at different temperatures.

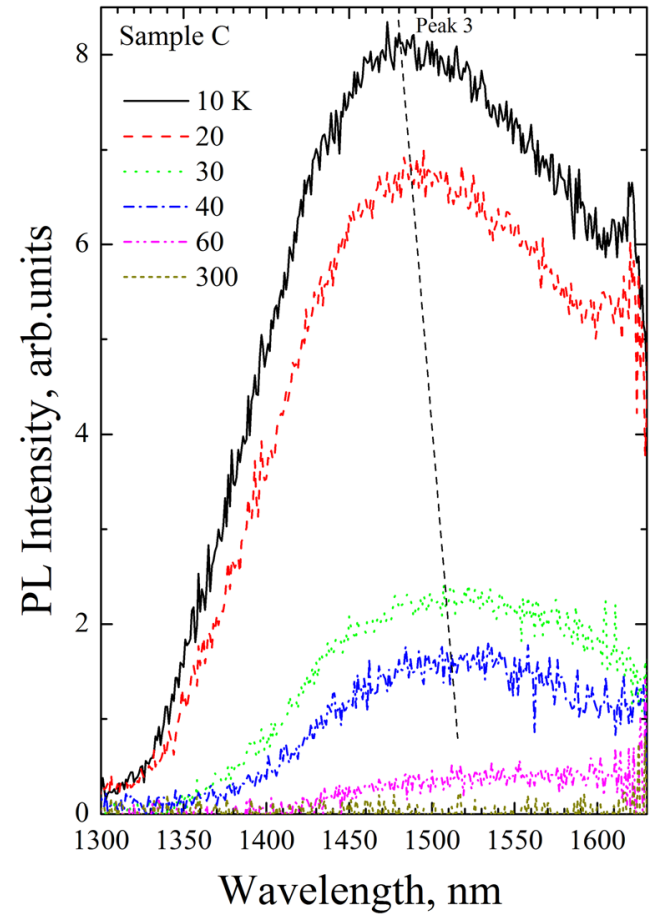

FIG. 5. PL spectra of sample $\mathrm{C}$ at different temperatures.

$$
\begin{aligned}
\mathrm{E}\left(\mathrm{In}_{\mathrm{x}} \mathrm{Ga}_{1-\mathrm{x}} \mathrm{As}, \mathrm{meV}\right)= & 420+625(1-\mathrm{x})+475(1-\mathrm{x})^{2} \\
& -\mathrm{x} T^{2}\left(\frac{0.58}{T+300}-\frac{0.49}{T+271}\right) \\
& -\frac{0.419 T^{2}}{T+271} .
\end{aligned}
$$

Assuming that the red-shift is due to temperature changes of the value of band gaps for $\mathrm{Ge}$ and $\mathrm{In}_{\mathrm{x}} \mathrm{Ga}_{1-\mathrm{x}} \mathrm{As}$, the effect as the temperature increases from 10 to $40 \mathrm{~K}$ for germanium (peak 3) shall be $2.7 \mathrm{meV}$, whereas according to the experimental data (Fig. 5), it is $18.8 \mathrm{meV}$. The situation is similar for peak 2, the temperature change of band gap for $\mathrm{In}_{0.37} \mathrm{Ga}_{0.63} \mathrm{As}$ as the temperature increases from 5 to $40 \mathrm{~K}$ should be $2.6 \mathrm{meV}$, whereas according to the experimental data (Fig. 4), the shift is $18 \mathrm{meV}$. The experimental red-shift of peak 1 is very close to the theoretical prediction (approximately $0.8 \mathrm{meV}$ for the temperature increase from 5 to $20 \mathrm{~K}$ ). So, one can suggest that peak 1 is due to the optical transitions between electrons and holes in the buffer layer $\mathrm{In}_{0.37} \mathrm{Ga}_{0.63} \mathrm{As}$. The band gap value of this solid alloy is $998 \mathrm{meV}$ at $10 \mathrm{~K}$. Figure 2 shows that peak 1 has the same position for samples A and B $(1073 \mathrm{meV})$. The match is obvious, since for samples $\mathrm{A}$ and $\mathrm{B}$, the Ge films were grown on the same buffer layer. The difference with the calculated value of band gap is about $75 \mathrm{meV}$, and it may be due to the fact that the solid alloy $\mathrm{In}_{0.37} \mathrm{Ga}_{0.63} \mathrm{As}$ is not relaxed completely (see Table I), the compressive strain leads to an increase in the band gap. Another reason could be that the electrons and holes can recombine remaining "hot," not thermalized at the bottoms of the corresponding valleys, because the energy of the exciting photon is quite high $(2541 \mathrm{meV}, \lambda=488 \mathrm{~nm})$. One additional reason of some increase in the energy of the emitted photon, compared with the band gap of $\operatorname{In}_{0.37} \mathrm{Ga}_{0.63} \mathrm{As}$ may be that in 

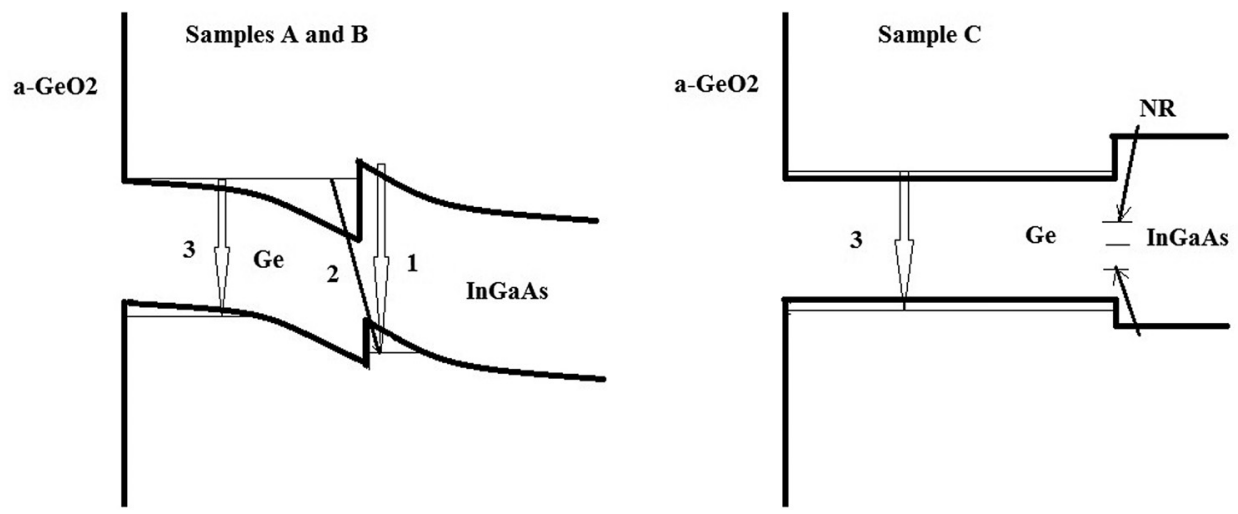

FIG. 6. Diagram of the band structure and optical transitions.

the case of a type-II heterostructure, in the presence of an electric field, the holes can be localized near the interface in the two-dimensional quantum well (see Fig. 6).

Peak 2 may be associated with indirect (in space) optical transitions between the electrons localized in $\mathrm{Ge}$, and the holes localized in the $\operatorname{In}_{0.37} \mathrm{Ga}_{0.63} \mathrm{As}$. In theory developed in Ref. 21, it is suggested that the blue-shift with increasing of laser fluence is due to the fact that localization in a quantum well charge carriers of one sign is cause of electric field that penetrates into the matrix. The electric field is the cause of triangle-shape quantum well for charge carriers of another sign in the matrix. The higher the laser fluence, the more carriers are generated and separated and the larger the electric field strength. The triangle-shape quantum well becomes narrower, and the energy of optical transitions becomes higher. Presumably, in our case there are deep traps for charge carriers associated with defects at the $\mathrm{Ge}-\mathrm{In}_{0.37} \mathrm{Ga}_{0.63} \mathrm{As}$ interface. The charged traps can screen the electric field, so that its value does not increase significantly with increasing of the laser fluence. One should note that the theory was developed for symmetric structure barrier/well/barrier, but the structure $\mathrm{GeO}_{2} / \mathrm{Ge} / \mathrm{InGaAs} / \mathrm{GaAs}$ is not symmetric. As it was mentioned above, the Ge films have native oxide. The heterostructure $\mathrm{GeO}_{2} / \mathrm{Ge}$ is a type-I heterostructure with band offset equal to $1.5 \mathrm{eV}$ for conduction bands and $3.4 \mathrm{eV}$ for the valence bands. ${ }^{25,26}$ The holes are localized in $\mathrm{In}_{0.37} \mathrm{Ga}_{0.63} \mathrm{As}$ because of the band offset for Ge and $\operatorname{In}_{0.37} \mathrm{Ga}_{0.63} \mathrm{As}{ }^{13}$ Since the dielectric permittivity of $\mathrm{Ge}$ is greater than that of $\mathrm{GeO}_{2}$ and vacuum, the image-charge has the same sign, ${ }^{27}$ and the electrons are pushed away from the $\mathrm{GeO}_{2} / \mathrm{Ge}$ interface, but the holes are attracted towards it (Fig. 6). The electric field from the electrons and from their image-charges is partially screened by charges at the $\mathrm{Ge} / \mathrm{In}_{0.37} \mathrm{Ga}_{0.63} \mathrm{As}$ interface, but it penetrates into the $\mathrm{In}_{0.37} \mathrm{Ga}_{0.63} \mathrm{As}$ matrix. In the matrix, the electric field is screened by free charges and its strength decreases in the depth of the matrix. Therefore, the triangular-shape well for holes (near the interface) is poorly modulated with an increase in the laser fluence, and the effect of blue-shift of peak 2 is barely visible (Fig. 3). Figure 2 shows that the position of peak 2 is different for samples A and $\mathrm{B}$, so, it depends on the strain relaxation in the Ge film, and probably the band offset is also dependent on strain.

Peak 3 is apparently due to optical transitions between electrons and holes in Ge films. Two effects have influence on its position. Tensile strain reduces the value of band gap and, accordingly, reduces the energy of the optical transitions. At the same time, the quantum size effect and electric field, separating the electrons and holes in space, increase the energy of the optical transitions. ${ }^{28}$ Finally, we note that the energy of peak (2) is larger than the energy of peak (3). A similar behavior was already reported by Pavarelli et al. $^{13}$ in $\mathrm{InGaAs} / \mathrm{Ge} / \mathrm{InGaAs}$ heterostructures. We expect that this may be due to the stoichiometry of the interface between the Ge film and the InGaAs buffer layer (either group-III or group-V atoms bonded to $\mathrm{Ge}$ atoms). Depending on these terminations, the difference in electronegativity between the atomic species leads to the creation of dipoles at the $\mathrm{Ge} / \mathrm{InGaAs}$ interface and thus to an electric field which modifies the bandstructure as shown in Fig. 6. This may eventually lead to a higher energy of peak (2) with respect to peak (3) as observed experimentally. Contrary to the assumption of increasing the probability of direct transitions (tensile strain in the sample $\mathrm{A}$ reaches $2.25 \%$ ), the intensity of peak 3 is small. Probably, it is because of defects at the interfaces. The deep defect states are centers for non-radiative recombination. The temperature dependence of the PL (Figs. 4 and 5) demonstrates the influence of a strong non-radiative recombination channel. When the temperature rises up to $40-60 \mathrm{~K}$, the PL signal practically disappears. In the type-II heterostructures $\mathrm{Ge} / \mathrm{Ge}_{0.5} \mathrm{Si}_{0.5}$, in which Ge films are compressed, there is also decrease in the PL intensity with increasing temperature, but not as strong, since the PL signal is present at temperatures up to $150-200 \mathrm{~K}$. ${ }^{29}$ The band gap of $\operatorname{In}_{\mathrm{x}} \mathrm{Ga}_{1-\mathrm{x}} \mathrm{As}$ increases with decrease of parameter $\mathrm{x}$, so, the heterostructure can become type-I. ${ }^{13}$ Figure 6 (right) shows an example of such structure (sample C). But in this case the tensile strain in the Ge film is small and does not reach the value where the transformation of $\mathrm{Ge}$ in direct-gap material is possible. Both electrons and holes are localized in $\mathrm{Ge}$, and do not create an electric field in the $\mathrm{In}_{0.33} \mathrm{Ga}_{0.67} \mathrm{As}$ matrix. Therefore, the PL spectrum of sample $\mathrm{C}$ does not present peaks 1 and 2 (Fig. 2). The probability of non-radiative recombination is also high, perhaps because of the deep traps at the interfaces and in the film. The traps (defects) can appear as a result of the relaxation of elastic stresses (dislocations). Non-radiative transitions are indicated in Figure 6 as NR. 


\section{CONCLUSIONS}

In conclusion, we note that in order to achieve both of the two conditions required for the strong PL intensity in the IR range from the Ge films (tensile strain of more than $2 \%$ and the band gap offsets, providing a type-I heterostructure), the following is needed. One should use a broader band gap material as a buffer, for example $\operatorname{In}_{\mathrm{x}} \mathrm{Al}_{1-\mathrm{x}} \mathrm{As}$ alloy. It is known that the band gap (in meV) for solid alloy $\operatorname{In}_{\mathrm{x}} \mathrm{Al}_{1-\mathrm{x}} \mathrm{As}$ depends on the stoichiometric parameter $\mathrm{x}$ as $E_{g}=3020-3390 x+740 x^{2} \quad$ (Refs. 30-32) and with the required parameter $(\mathrm{x}=0.37)$ is $1870 \mathrm{meV}$. This is almost two times more than that of $\operatorname{In}_{0.37} \mathrm{Ga}_{0.63} \mathrm{As}$ and it gives us hope that in such a heterostructure one can achieve a high probability of optical transitions from Ge films in IR range.

\section{ACKNOWLEDGMENTS}

V. A. Volodin is thankful to the administration of Université de Lorraine for a visit grant during 2013. The authors are thankful to the administration of Research and the Education Center "Nanosystems and Modern Materials" at Novosibirsk State University for the possibility to use the Raman spectrometer. The work was partly supported by RFBR, project 13-02-00259.

${ }^{1}$ M. V. Fischetti and S. E. Laux, J. Appl. Phys. 80, 2234 (1996).

${ }^{2}$ F. Zhang, V. H. Crespi, and P. Zhang, Phys. Rev. Lett. 102, 156401 (2009).

${ }^{3}$ M. El Kurdi, G. Fishman, S. Sauvage, and P. Boucaud, J. Appl. Phys. 107, 013710 (2010).

${ }^{4}$ S. Takeuchi, Y. Shimura, O. Nakatsuka, S. Zaima, M. Ogawa, and A. Sakai, Appl. Phys. Lett. 92, 231916 (2008).

${ }^{5}$ Y. Shimura, N. Tsutsui, O. Nakatsuka, A. Sakai, and S. Zaima, Thin Solid Films 518, S2 (2010).

${ }^{6}$ Y. Huo, H. Lin, R. Chen, M. Makarova, Y. Rong, M. Li, T. I. Kamins, J. Vuckovic, and J. S. Harris, Appl. Phys. Lett. 98, 011111 (2011).

${ }^{7}$ R. Jakomin, M. de Kersauson, M. El Kurdi, L. Largeau, O. Mauguin, G. Beaudoin, S. Sauvage, R. Ossikovski, G. Ndong, M. Chaigneau, I. Sagnes, and P. Boucaud, Appl. Phys. Lett. 98, 091901 (2011).

${ }^{8}$ S.-R. Jan, C.-Y. Chen, C.-H. Lee, S.-T. Chan, K.-L. Peng, C. W. Liu, Y. Yamamoto, and B. Tillack, Appl. Phys. Lett. 98, 141105 (2011).
${ }^{9}$ J. R. Sánchez-Pérez, C. Boztug, F. Chen, F. F. Sudradjat, D. M. Paskiewicz, R. B. Jacobson, M. G. Lagally, and R. Paiella, Proc. Natl. Acad. Sci. U.S.A. 108, 18893 (2011).

${ }^{10}$ X. Wang, L. C. Kimerling, J. Michel, and J. Liu, Appl. Phys. Lett. 102, 131116 (2013).

${ }^{11}$ R. E. Camacho-Aguilera, Y. Cai, N. Patel, J. T. Bessette, M. Romagnoli, L. C. Kimerling, and J. Michel, Opt. Express 20, 11316 (2012).

${ }^{12}$ J. Liu, X. Sun, R. E. Camacho-Aguilera, L. C. Kimerling, and J. Michel, Opt. Lett. 35, 679 (2010).

${ }^{13}$ N. Pavarelli, T. J. Ochalski, F. Murphy-Armando, Y. Huo, M. Schmidt, G. Huyet, and J. S. Harris, Phys. Rev. Lett. 110, 177404 (2013).

${ }^{14}$ E. Anastassakis, A. Pinczuk, and E. Burstein, Solid State Commun. 8, 133 (1970).

${ }^{15}$ F. Cerdeira, C. J. Buchenauer, F. H. Pollak, and M. Cardona, Phys. Rev. B 5, $580(1972)$

${ }^{16}$ Z. Sui, H. H. Burke, and I. P. Herman, Phys. Rev. B 48, 2162 (1993).

${ }^{17}$ J. Groenen, R. Carles, S. Christiansen, M. Albrecht, W. Dorsch, H. P. Strunk, H. Wawra, and G. Wagner, Appl. Phys. Lett. 71, 3856 (1997).

${ }^{18}$ V. A. Volodin, M. D. Efremov, A. S. Deryabin, and L. V. Sokolov, Semiconductors 40, 1314 (2006).

${ }^{19}$ Yu. B. Bolkhovityanov, A. P. Vasilenko, A. K. Gutakovskii, A. S. Deryabin, M. A. Putyato, and L. V. Sokolov, Phys. Solid State 53, 2005 (2011).

${ }^{20}$ R. R. Lieten, K. Bustillo, T. Smets, E. Simoen, J. W. Ager III, E. E. Haller, and J.-P. Locquet, Phys. Rev. B 86, 035204 (2012).

${ }^{21}$ N. N. Ledentsov, J. Bohrer, M. Beer, F. Heinrichsdorff, M. Grundmann, D. Bimberg, S. V. Ivanov, B. Ya. Meltser, S. V. Shaposhnikov, I. N. Yassievich, N. N. Faleev, P. S. Kop'ev, and Zh. I. Alferov, Phys. Rev. B 52, 14058 (1995).

${ }^{22}$ Y. P. Varshni, Physica 34, 149 (1967).

${ }^{23}$ S. M. Sze, Physics of Semiconductor Devices, 2nd ed. (John Wiley and Sons, New York, 1981).

${ }^{24}$ S. Paul, J. B. Roy, and P. K. Basu, J. Appl. Phys. 69, 827 (1991).

${ }^{25}$ P. Broqvist, J. Felix Binder, and A. Pasquarello, Appl. Phys. Lett. 94, 141911 (2009).

${ }^{26}$ P. Broqvist, J. Felix Binder, and A. Pasquarello, Appl. Phys. Lett. 98, 129901 (2011).

${ }^{27}$ L. D. Landau and E. M. Lifshitz, Electrodynamics of Continuous Media, 1st ed. (Pergamon Press, 1960), Vol. 8.

${ }^{28}$ V. Ya. Aleshkin and A. A. Dubinov, J. Appl. Phys. 109, 123107 (2011).

${ }^{29}$ R. Aluguri, S. Manna, and S. K. Ray, Appl. Phys. Lett. 103, 161118 (2013).

${ }^{30}$ B. Wakefield, M. A. G. Halliwell, T. Kerr, D. A. Andrews, G. J. Davies, and D. R. Wood, Appl. Phys. Lett. 44, 341 (1984).

${ }^{31}$ Self-Assembly of Nanostructures: The INFN Lectures, edited by $\mathrm{S}$. Bellucci (Springer Verlag, New York, 2012), Vol. III.

${ }^{32}$ V. A. Volodin, M. P. Sinyukov, V. A. Sachkov, M. Stoffel, H. Rinnert, and M. Vergnat, Europhys. Lett. (to be published). 